\title{
Atividade Antifúngica de Óleos Essenciais de Espécies de Piper Sobre Crinipellis perniciosa, Phytophthora palmivora e Phytophthora capsici
}

\author{
Danielle Mariana M.H. Silva ${ }^{1}$ \& Cleber N. Bastos² \\ ${ }^{1}$ Instituto de Desenvolvimento Rural do Amapá, Av. Antônio Coelho de Carvalho, 2267, apto. G, CEP 68000-900, \\ Macapá, AP, Brasil; ${ }^{2}$ Comissão Executiva do Plano da Lavoura Cacaueira, Estação de Recursos Genéticos José Haroldo, \\ Cx. Postal 46, CEP 67150-970, Marituba, PA, Brasil, e-mail: cleber@ufpa.br
}

Autor para correspondência: Cleber N. Bastos

SILVA, D.M.H. \& BASTOS, C.N. Atividade antifúngica de óleos essenciais de espécies de Piper sobre Crinipellis perniciosa, Phytophthora palmivora e Phytophthora capsici. Fitopatologia Brasileira 32:143-145. 2007.

\section{RESUMO}

Avaliou-se in vitro, a atividade fungitóxica do óleo essencial em diferentes concentrações extraído de 10 espécies de Piper coletadas na região Amazônica, sobre o crescimento micelial e a germinação de basidiósporos de Crinipellis perniciosa e sobre o crescimento micelial de Phytophthora palmivora e P. capsici. Os óleos mais efetivos que inibiram em $100 \%$ o crescimento dos três fungos foram os de $P$. callosum, $P$. marginatum var. anisatum e $P$. enckea, nas concentrações de $0,75 \mu \mathrm{L} / \mathrm{mL}$ e $1 \mu \mathrm{L} / \mathrm{mL}$. Quanto à germinação de basidiósporos de $C$. perniciosa, o óleo de $P$. dilatatum foi o mais eficiente a $0,4 \mu \mathrm{L} / \mathrm{mL}$ seguido pelos óleos de $P$. callosum e $P$. marginatum var. anisatum a $0,5 \mu \mathrm{L} / \mathrm{mL}$.

Palavras-chave adicionais: Vassoura-de-bruxa, podridão parda, cacaueiro, controle.

\begin{abstract}
Antifungal activity of essential oils of Piper species against Crinipellis perniciosa, Phytophthora palmivora and Phytophthora capsici

Ten essential oils extracted from species of Piper collected in the Amazon region were evaluated in vitro according to their effectiveness in inhibiting mycelial growth and basidiospore germination of Crinipellis perniciosa and in inhibiting mycelial growth of Phytophthora palmivora and $P$. capsici. The essential oils of $P$. callosum, $P$. marginatum var. anisatum and $P$. enckea were most effective, causing $100 \%$ inhibition of the three fungi in concentrations of $0.75 \mu \mathrm{L} / \mathrm{mL}$ and $1.0 \mu \mathrm{l} /$ $\mathrm{mL}$. For basidiospore germination, the oil of $P$. dilatatum was the best at $0.4 \mu \mathrm{L} / \mathrm{mL}$ concentration, followed by the oils of $P$. callosum and P. marginatum var. anisatum at $0.5 \mu \mathrm{L} / \mathrm{mL}$.
\end{abstract}

Additional keywords: Witches broom disease, fruit pod rot, cocoa, control.

Problemas de poluição do meio ambiente e efeitos tóxicos de produtos químicos sintéticos aos organismos não alvo estimularam as pesquisas em torno do potencial de pesticidas de origem vegetal (Amadioha, 2000). Os produtos naturais de origem vegetal e seus análogos são uma importante fonte de novos defensivos agrícolas usados no controle de doenças de plantas. Dentre esses produtos, os óleos essenciais, caracterizados como metabólitos secundários de plantas e de baixa toxicidade a mamíferos, são amplamente testados no controle de fitopatógenos. O óleo essencial extraído de Caesulia axillaris foi relatado ser superior a oito fungicidas sintéticos e foi mais eficaz no controle da mancha foliar do arroz, causada por Helminthosporium oryzae (Amadioha, 2000). Alves et al. (2003) relataram a eficiência dos óleos de Cymbopogon nardus, C. citratus e Eucalyptus citriodora no controle in vitro dos fungos Colletotrichum gloeosporioides, C. musae e Fusarium subglutinans f. sp. ananas. Almeida et al. (2004), testando in vitro extratos de folhas e óleos essenciais contra o fungo Diaporthe citri, verificaram que o óleo de nim foi o mais eficiente na inibição do crescimento micelial do fungo.
A Amazônia com sua biodiversidade é uma grande fonte de recursos naturais para obtenção de substâncias fungitóxicas com potencial para utilização no controle de doenças de plantas. A família Piperaceae descrita por Paul Dietrich Giseki compreende aproximadamente três mil espécies distribuídas em oito gêneros (Di Stasi et al., 2002), dos quais se destacam os gêneros Piper, Peperomia e Pothormorphe. O gênero Piper é o que tem maior número de espécies, próximo de 700 , distribuídas em todas as regiões tropicais, das quais mais de 170 ocorrem no Brasil (Yuncker, 1972). Da Amazônia, várias espécies já foram estudadas como P. belte, P. nigrum, P. amapaense, P. duckei, $P$. bartlingianum, $P$ arboreum. As espécies de Piper são grandes produtoras de óleos essenciais (Maia et al., (1977).

A atividade biológica de espécies de Piper é muita diversificada e também muito utilizada na medicina popular para tratamento de inúmeras doenças (Vieira, 1992; Di Stasi, 2000; Lorenzi \& Matos, 2002).

No controle de doenças em plantas Tewari \& Nayak (1991) demonstraram que extratos de folhas de $P$. belte foram efetivos em reduzir o crescimento micelial de vários 
patógenos que atacam o arroz. Extratos de folhas e o óleo essencial de $P$. aduncum foram efetivos sobre a germinação de basidiósporos e crescimento micelial de Crinipellis perniciosa (Stahel) Singer e, sobre o crescimento de outros fitopatógenos (Bastos, 1997).

O objetivo deste trabalho foi avaliar in vitro a ação fungitóxica de óleos essenciais extraídos de folhas de espécies de Piper coletadas na região amazônica, contra os fungos C. perniciosa, causador da vassoura-de-bruxa em cacaueiro, Phytophthora palmivora (E.J. Butler) E.J. Butler e Phytophthora capsici Leonian, causadores da podridão parda em frutos de cacaueiros.

As espécies de Piper usadas foram Piper dilatatum Rich., P. cyrtopodon (Miq.) C. DC., P. hostmannianum (Miq.) C. DC., P. callosum Ruiz \& Pav., P. tuberculatum Jacq., $P$. divaricatum G. Mey, P. nigrispicum C. DC e P. hispidum Sw., coletadas nas áreas da Estação de Recursos Genéticos do Cacau (ERJOH), município de Marituba, PA. As espécies Piper marginatum var. anisatum Jacq. e P. enckea C. DC. foram coletadas nas áreas da Estação Experimental Paulo Morelli (ESPAM), município de Medicilândia, PA. Exsicatas das plantas foram encaminhadas para identificação no Museu Paraense Emílio Goeldi (MPEG) e Jardim Botânico do Rio de Janeiro.

Para extração dos óleos, as folhas foram secas à sombra em temperatura ambiente, trituradas e, em seguida submetidas ao processo de hidrodestilação em aparelhos de tipo Clevenger.

Nos testes de inibição do crescimento micelial dos fungos, foram usadas alíquotas dos óleos incorporadas ao meio de batata dextrose ágar (BDA) fundente, de modo a se obter concentrações de $0,1 \mu \mathrm{L} / \mathrm{mL}, 0,25 \mu \mathrm{L} / \mathrm{mL}, 0,5 \mu \mathrm{L} / \mathrm{mL}, 0,75$ $\mu \mathrm{L} / \mathrm{mL}$ e $1 \mu \mathrm{L} / \mathrm{mL}$ e, vertido em placas de Petri de $9,0 \mathrm{~cm}$ de diâmetro. Para as testemunhas, foram usadas placas contendo apenas BDA. Após a solidificação do meio, discos de $0,7 \mathrm{~cm}$ de diâmetro contendo micélio de cada um dos fungos, foram transferidos para o centro das placas. Estas foram incubadas em câmara de crescimento com temperatura controlada para $25 \pm 1$ ${ }^{\circ} \mathrm{C}$, em ausência de luz. As avaliações foram feitas quando o crescimento micelial da testemunha cobriu totalmente a superfície do meio de cultura e a ação fungitóxica dos óleos sendo determinada através da concentração inibitória mínima (CIM), expressa em $\mu \mathrm{L} / \mathrm{mL}$, que representa a mais baixa concentração necessária para causar total inibição do crescimento micelial dos fungos. Para cada tratamento óleo/concentração foram empregadas quatro repetições.

Adicionalmente foi avaliado o efeito inibitório dos óleos contra a germinação de basidiósporos de C. perniciosa. Para tanto, utilizaram-se lâminas escavadas, contidas no interior de placas de Petri sobre papel de filtro umedecido em água destilada. Em cada lâmina foram depositados 100 $\mu \mathrm{L}$ das concentrações dos óleos emulsionados em água destilada esterilizada, e a seguir, colocado $10 \mu \mathrm{L}$ de uma suspensão de basidiósporos ( 1 x $10^{5}$ esporos $\left./ \mathrm{mL}\right)$. Para cada tratamento foram usadas três repetições. Após 24 horas de incubação à temperatura de $25 \pm 1^{\circ} \mathrm{C}$, adicionou-se gotas de lactofenol-azul de algodão para avaliação microscópica da germinação e determinada a concentração inibitória mínima (CIM). Foram considerados como basidiósporos germinados aqueles que apresentaram tubo germinativo independente de seu comprimento. Em cada lâmina foram contados 100 basidiósporos em três diferentes campos do microscópio, no aumento de 40x.

Os resultados obtidos demonstraram que o crescimento micelial de $C$. perniciosa foi inibido em $100 \%$ a partir da concentração de $0,75 \mu \mathrm{L} / \mathrm{mL}$ do óleo de $P$. callosum e na concentração de $1 \mu \mathrm{L} / \mathrm{mL}$ do óleo de $P$. marginatum var. anisatum (Tabela 1). Para a ocorrência de $100 \%$ de inibição do crescimento de P. palmivora, os óleos de P. callosum (1 $\mu \mathrm{L} / \mathrm{mL})$ e $P$. enckea $(1 \mu \mathrm{L} / \mathrm{mL})$ mostraram mais efetivos, enquanto que, os demais óleos testados praticamente não apresentaram ação inibitória (Tabela 1). Quanto a P. capsici foi verificado que apenas o óleo de $P$. callosum provocou $100 \%$ de inibição nas concentrações de $0,75 \mu \mathrm{L} / \mathrm{mL}$.

$\mathrm{O}$ óleo de $P$. callosum possui na sua composição vários componentes como safrol (64\%), metil-eugenol (2,69\%), $\alpha$-pineno (6,9\%) (Maia et al., 2000). No estudo químico dos componentes fixos de $P$. callosum, realizado por Facundo et al. (2004), foram isoladas três flavonas, duas pentaoxigenadas e uma tetraoxigenada. Os flavonóides altamente oxigenados, como os presentes em $P$. callosum, são dotados de atividade antimicrobiana. Segundo Silva (2001), a reunião de vários componentes na composição de óleos essenciais, pode atuar em harmonia sinergética e apresentar uma ampla gama de atuação fungicida ou fungistática.

Com relação à ação dos óleos sobre os basidiósporos de $C$. perniciosa, foi verificado que os óleos de $P$. dilatatum,

TABELA 1 - Efeito de concentração inibitória mínima (CIM) dos óleos essenciais de Piper spp. no crescimento micelial de Crinippelis perniciosa, Phytophthora palmivora e P. capsici

\begin{tabular}{|c|c|c|c|}
\hline \multirow[t]{2}{*}{ Óleos } & \multirow[b]{2}{*}{ C. perniciosa } & \multicolumn{2}{|c|}{$\mathbf{C I M}^{*}(\mu \mathbf{L} / \mathbf{m L})$} \\
\hline & & P. palmivora & P.capsi \\
\hline Piper dilatatum & $>1,0$ & $-* *$ & $>1,0$ \\
\hline P. cyrtopodon & $>1,0$ & - & - \\
\hline P. hostmannianum & - & - & - \\
\hline P. callossum & 0,75 & 1,0 & 0,75 \\
\hline P. tuberculatum & $>1,0$ & - & - \\
\hline P. marginatum var. anisatum & 1,0 & $>1,0$ & $>1,0$ \\
\hline P. enckea & $>1,0$ & 1,0 & $>1,0$ \\
\hline P. divaricatum & $>1,0$ & - & - \\
\hline P. nigrispicum & - & - & - \\
\hline P. hispidum & - & - & - \\
\hline
\end{tabular}


P. callosum e $P$. marginatum var. anisatum foram os mais eficazes, sendo capazes de causar total inibição na germinação nas concentrações de $0,4 \mu \mathrm{L} / \mathrm{mL}, 0,5 \mu \mathrm{L} / \mathrm{mL}$ e $0,5 \mu \mathrm{L} /$ $\mathrm{mL}$, respectivamente (Tabela 2). Os dados mostram que os basidiósporos foram mais sensíveis a esses óleos do que o micélio do patógeno (Tabela 1). Isto é relevante, uma vez que os basidiósporos são as principais unidades infectivas do patógeno, que após a liberação do píleo ou chapéu dos basidiomas são

TABELA 2 - Efeito da concentração inibitória mínima (CIM) dos óleos essenciais de Piper spp. na germinação de basidiósporos de Crinipellis perniciosa, in vitro

\begin{tabular}{ll}
\hline \hline Óleos & $\mathrm{CIM}^{*}(\mathrm{~L} / \mathrm{mL})$ \\
\hline Piper dilatatum & 0,4 \\
P. cyrtopodon & 30,0 \\
P. hostmaniannum & 30,0 \\
P. ca llossum & 0,5 \\
P. tuberculatum & 30,0 \\
P. marginatum var. anisatum & 0,5 \\
P. enckea & 3,0 \\
P. divaricatum & 100,0 \\
P. nigrispicum & 1,0 \\
P. hispidum & 70,0 \\
\hline
\end{tabular}

*CIM - Concentração inibitória mínima, em $\mu \mathrm{L} / \mathrm{mL}$, requerida para causar total inibição na germinação dos basidiósporos.

levados pelas correntes aéreas e, em conseqüência, podendo infectar ramos vegetativos e frutos jovens, em cacaueiros suscetíveis à vassoura-de-bruxa.

No presente trabalho não foi relacionado para teste o óleo de $P$. aduncum. O óleo desta piperácea é rico em dilapiol, com comprovada ação inibitória contra um grande número de fitopatógenos, inclusive $C$. perniciosa, $P$. palmivora e $P$. capsici (Bastos \& Silva, 2002).

Os resultados obtidos demonstraram que os óleos essenciais de $P$. callosum, $P$. marginatum var. anisatum e $P$. enckea tiveram ação fungitóxica significativa contra os três fitopatógenos testados. Isto indica, portanto, boas perspectivas para uso experimental desses óleos no controle dos fitopatógenos em condições de casa-de-vegetação e de campo. A possibilidade de uso de produtos de origem natural, que apresentam baixa toxicidade, se traduz em vantagem por ser um procedimento menos agressivo ao meio ambiente.

\section{AGRADECIMENTOS}

Os autores agradecem à Dra. Léa Maria Carreira, do Museu Paraense Emílio Goeldi (MPEG) e à Dra. Elsie
Guimarães, do Jardim Botânico do Rio de Janeiro pela classificação e identificação das espécies botânicas.

\section{REFERÊNCIAS BIBLIOGRÁFICAS}

ALMEIDA, T.F., PEREIRA, C.F., CAMARGO, M. \& PANIZZI, R.C. Efeito do óleo de nim e extratos vegetais de Azadirachia indica, Cymbopogon citratus e Zingiber officinale no crescimento micelial in vitro de Diaporthe citri. Summa Phytopathologica 30:116. 2004. (Resumo)

ALVES, E.S.S.B., PUPO, M.S., MARQUES, S.S., VILCHES, T.T.B., SANTOS, R.B., VENTURA, J.A. \& FERNANDO, P.M.A Avaliação de óleos essenciais na inibição do crescimento de fungos de fruteiras tropicais. Fitopatologia Brasileira 28 (Supl.):343. 2003.

AMADIOHA, A.C. Controlling rice blast in vitro and in vivo with extracts of Azadirachia indica. Crop Protection 19:287-290. 2000.

BASTOS, C.N. Efeito do óleo de Piper aduncum sobre Crinipellis perniciosa e outros fungos fitopatogênicos. Fitopatologia Brasileira 22:441-443. 1997.

BASTOS, C.N. \& SILVA, D.M.H. Inibição micelial de fungos fitopatógenos através de óleos essenciais de Piper aduncum e $P$. marginatum. Fitopatologia Brasileira 27 (Supl.):82. 2002.

DI STASI, L.C., HIRUMA-LIMA, C.A., SOUZA-BRITO, A.R.M., MARIOT, A. \& SANTOS, C.M. Plantas medicinais na Amazônia e na Mata Atlântica. 2a ${ }^{\text {a }}$ Ed. São Paulo SP. Editora UNESP. 2002.

FACUNDO, V.A., MORAIS, S.M. \& FILHO, R.B. Flavonóides de Piper callosum da Amazônia. http://www.sbq.org.br/anteriores/23/ resumos/0765-2. Acesso em 01/07/2004.

LORENZI, H. \& MATOS, F.J.A. Plantas medicinais no Brasil: nativas e exóticas. Nova Odessa SP. Instituto Plantarum. 2002.

MAIA, J.G., ZOGHBI, M.G., ANDRADE, E.H.A., SANTOS, A.S. \& SILVA, M.H.L. Banco de dados das Plantas Aromáticas da Amazônia: Inventário das Espécies de Piper. Belém PA. Relatório Final à Academia Brasileira de Ciências, MPEG. 1997.

MAIA, J.G.S., ZOGHBI, M. G. B. \& ANDRADE, E. H. A. Plantas Aromáticas na Amazônia e Seus Óleos Essenciais. Belém PA. Museu Paraense Emílio Goeldi. 2000.

SILVA, A.R. Tudo sobre aromaterapia: como usá-la para melhorar sua saúde física, emocional e financeira. 2a . Ed. São Paulo SP. Editora Roca Ltda. 2001.

TEWARI, S.N. \& NAYAK, M. Activity of four-plant extracts against three pathogens of rice. Tropical Agriculture (Trinidad) 68:373-375. 1991.

VIEIRA, L.S. Fitoterapia da Amazônia: Manual de Plantas Medicinais. 2a ${ }^{\mathrm{a}}$ Ed. São Paulo SP. Editora Ceres. 1992.

YUNCKER, T.G. The Piperaceae of Brazil. Hoehnea 2:19-366. 1972. 